\title{
O PROCESSO AUTOPOIÉTICO E A CONSTRUÇÃO DA EDUCAÇÃO CIDADÃ NAS ESCOLAS DE ENSINO FUNDAMENTAL A PARTIR DE NIKLAS LUHMANN
}

\section{THE AUTOPOIETIC PROCESS AND THE CONSTRUCTION OF CITIZEN EDUCATION IN ELEMENTARY SCHOOLS FROM NIKLAS LUHMANN}

\author{
Melissa Zani Gimenez ${ }^{1 a}$ \\ Josiane Rose Petry Veronese ${ }^{1 b}$
}

Data de recebimento: 06/03/2018

Data de Aprovação: 17/08/2018

\section{RESUMO}

Este artigo visa a demonstrar a possibilidade de o Sistema Educacional reverter o processo de judicialização do Sistema Jurídico, o qual tem por função organizar parte da complexidade existente no Sistema Social, com vistas a reduzir a contingência presente na amplitude de relações e sentidos enquanto meios do sistema. Este estudo é resultado de sondagem realizada, no ano de 2016, com um corpus de 26 (vinte e seis) crianças, integrantes do terceiro ano

\footnotetext{
${ }^{1 a}$ Professora. Advogada. Doutoranda na Pontífica Universidade Católica de São Paulo- PUC/SP- com bolsa CNPQ- sob a orientação do professor Willis Santiago Guerra Filho. Mestre em Teoria Geral do Direito e do Estado pelo Centro Universitário Eurípedes de Marília, por intermédio da bolsa CAPES / PROSUP ? modalidade I. Dedica-se à pesquisa acadêmica relativa ao tema: Educação do Estatuto da Criança e do Adolescente nas Escolas de Ensino Fundamental para a formação ético-social do educando junto ao Grupo de Pesquisa GEP - Grupo de Estudos, Pesquisas, Integração e Práticas Interativas- ProfessoresLafayette Pozzoli e Clarissa Chagas Sanches Monassa e também junto ao Grupo de Pesquisa GIS- Direitos dos Grupos Vulneráveis e Inclusão Social-Professoras-Viviane Rigoldi e Daniela Marinho.

Endereço eletrônico: \&lt;melissazanigimenez@gmail.com\&gt;.

${ }^{1 b}$ Professora Titular da disciplina Direito da Criança e do Adolescente, da Universidade Federal de Santa Catarina, na graduação e nos Programas de Mestrado e Doutorado em Direito. Doutora e Mestre em Direito pela Universidade Federal de Santa

Catarina. Pós-doutorado na Faculdade de Serviço Social da PUC/RS. Coordenadora do NEJUSCA - Núcleo de Estudos Jurídicos e Sociais da Criança e do Adolescente e subcoordenadora do Núcleo de Pesquisa Direito e Fraternidade do Centro de Ciências Jurídicas/UFSC. Acadêmica da Cadeira n. 1 da Academia de Letras de Biguaçu./SC. /http://lattes.cnpq.br/3761718736777602. E-mail: jpetryve@uol.com.br
} 
do ensino fundamental de uma escola pública no interior do Estado de São Paulo. Tal pesquisa verteu-se à promoção de atividades educacionais relacionadas ao Estatuto da Criança e do Adolescente, convergindo para a construção da consciência ético-social da pessoa em desenvolvimento. $\mathrm{O}$ ensino-aprendizagem do Estatuto da Criança e do Adolescente aconteceu durante todo o ano letivo e os resultados evidenciaram mudanças comportamentais e de concepções, aumento da segurança, autoestima e capacidade argumentativa por parte das crianças, maior frequência escolar, além de maior participação dos pais ou responsáveis na vida escolar dos alunos, consequentemente, uma nova autopoiese social. Para tal investigação, optou-se pela abordagem metodológica qualitativa, que compreende a observação, o registro e a análise dos dados por meio de categorias descritivas; utilizando-se, ainda, questionários com perguntas abertas.

\section{PALAVRAS-CHAVE}

Sistema Judiciário; Sistema Educacional; Desjudicialização; Estatuto da Criança e do Adolescente; Autopoiese social.

\section{ABSTRACT}

This article aims to demonstrate the possibility of the Educational System to reverse the process of judicialization of the Legal System, whose function is to organize part of the complexity in the Social System, with a view to reducing the present contingency in the dimnesion of relations and meanings as means of the system . This study is the result of a survey conducted in the year 2016 with a corpus of 26 (twenty six) children, members of the third year of elementary school at a public school of São Paulo. This research was directed to the promotion of educational activities related to the Brazilian Child and Adolescent Statute, converging to the construction of the ethical-social conscience of the developing person. The teaching and learning about the Statute happened throughout the school year and the results showed behavioral changes and conceptions, increased safety, self-esteem and argumentative capacity on the part of the children, higher school 
attendance, and greater parental involvement or responsible in the students' school life, consequently, a new social autopoiesis. For this investigation, we opted for the qualitative methodological approach, which includes the observation, recording and analysis of data by means of descriptive categories; using questionnaires with open questions.

\section{KEYWORDS}

Judicial System; Educational System; Dejudicialization; Child and Adolescent Statute; Social Autopoiesis. 


\section{INTRODUÇÃO}

De acordo com a teoria dos sistemas do filósofo e sociólogo alemão Niklas Luhmann², as pessoas são consideradas parte do ambiente dos Sistemas Sociais, atuando coadunadas a esses em cada circunstância que tomam parte na comunicação. Os sistemas trabalham operacionalmente fechados, não recebendo interferências externas e, por meio do mecanismo da autopoiese, constroem os próprios elementos de seu funcionamento (LUHMANN, 19271998; 2011).

Nesse contexto, destaca-se que a comunicação é o elemento central de composição dos Sistemas Sociais, sendo sua função orquestrar a auto-observação dos indivíduos que abarcam esse todo, não somente para acrescer conhecimentos, mas, também, para facultar a tangibilidade dos componentes. Os indivíduos não são mais considerados agentes sociais por excelência; antes, integram o ambiente da sociedade, estando a ela adstritos por conta das comunicações existentes. As comunicações são moderadas dentro dessas organizações preexistentes e apenas produzem e adquirem sentido nesse sistema específico.

Luhmann defende que o homem, seja corpo, seja consciência, é formante do ambiente da sociedade; logo, não representa uma fração isolada da sociedade. As unidades medulares da sociedade são as comunicações e, nesse ínterim, as pessoas representam construções sociais, sendo analisadas como "endereços dos processos comunicacionais".

Na comunicação luhmanniana, a interlocução por ser considerada realidade emergente, somente acontecendo pela junção de três aspectos: a informação, a comunicação e o entendimento. Dessa forma, o simples transmitir de conhecimentos não é suficiente para produzir comunicação, restringindose, tão somente, à formulação de percepções.

Nessa lógica, diante dos desarranjos comunicacionais presentes nos ambientes sociais, em especial na sociedade brasileira, uma sobrecarga de

\footnotetext{
${ }^{2}$ Dentre as principais obras publicadas por Niklas Luhmann encontram-se: A realidade dos meios de comunicação, Introdução à teoria dos sistemas, $\mathrm{O}$ direito da sociedade, entre outras que o tornaram um dos autores de Ciências Sociais mais produtivos do século $X X$.
} 
ações tem sido verificada no Sistema do Direito, sobretudo no Sistema Judiciário, quando formas brutas de solução são arrostadas para as contingências sociais provenientes dos ambientes do sistema.

Como consequência desses processos, o Sistema Educacional passa a significar um instrumento de grande valia para reverter a cultura do litígio. Já em seara complementar, observa-se, ademais, que algumas possibilidades do ambiente, particularmente, chamam a atenção do âmbito escolar, ou seja, evidenciam-se com potencial suficiente para irritá-lo. À vista de tais parâmetros, pois, esta análise cinge-se do apelo que existe para o estudo da necessidade de uma educação ético-social voltada à formação de uma nova autopoiese social, destinada à desjudicialização ${ }^{3}$ das relações sociais.

Nesse contexto, a educação estatutária trata-se de uma estratégia pedagógica capaz de possibilitar uma plena inserção da criança e do adolescente na sociedade, educando, pois, as pessoas em formação para um novo despertar, como possibilidade de prevenção e, respectiva, redução do ato infracional praticado pela criança e pelo adolescente.

No mundo contemporâneo, muito se tem discutido sobre a educação moral que está sendo construída e, de certo modo, precária e, em certos casos, ausente dentro da órbita familiar. $\mathrm{O}$ alto índice de atos infracionais e o despreparo que a pessoa em desenvolvimento está demonstrando no seu convívio social enfatizam a necessidade da realização de uma educação cidadã nas instituições escolares. A deficiência encontrada na educação informal repercute na necessidade de uma educação formal, como uma preocupação real em assegurar a inclusão de meninos e meninas diante do processo civilizatório; possibilidade de prevenção e, respectiva, redução do ato infracional praticado pela criança e pelo adolescente.

Nos centros escolares, dentre as tarefas realizadas pelo professor, está

\footnotetext{
${ }^{3}$ De acordo com André Ramos Tavares considera-se desjudicialização a desburocratização do Direito e, consequentemente, do Poder Judiciário. Nesses casos, a desjudicialização opera uma limpeza, deixando ao Judiciário o que é sua função própria, liberando-o de deveres secundários. [...] a consciência jurídica do cidadão é convocada a atuar civicamente, desestimulando-se que o Judiciário sirva como depositário primeiro e imediato do mero inconformismo entre interessados. A prática de descarregar demandas no Judiciário para que este encontre, isoladamente, as melhores e mais sábias soluções, não atende à melhor proposta de acesso à Justiça. TAVARES, André Ramos. Desjudicialização. Jornal Carta Forense. Disponível em:< http://www. cartaforense.com.br/conteudo/colunas/desjudicializacao/10165>. Acesso em 22 fev. 2018.
} 
o desenvolvimento junto às crianças, do processo de ensino-aprendizagem de regras ético-sociais, que demonstre o que é a sociedade, como se formaram e se transformaram com o passar dos tempos, os valores morais que a norteiam e o papel que o ser humano, cidadão, desempenha.

O presente Relato de Experiência representa, desse modo, uma pesquisa implementada com crianças de ensino fundamental de uma escola pública do interior do Estado de São Paulo. Primeiramente, foi discutida a Lei $\mathrm{n}^{\mathrm{o}} 11.525 / 2007^{4}$ e, após, problematizados os motivos de se trabalhar com o Estatuto da Criança e do Adolescente (ECA) no espaço escolar. Na continuidade, passou-se a uma discussão sobre o trabalho com o Estatuto enquanto ação educacional em direitos humanos, isto é, como instrução configurada em consonância com a educação em direitos humanos - recente área de estudo no campo educacional. Seguida a fundamentação teórica, houve a descrição detalhada da pesquisa, incluindo aspectos metodológicos, estratégias didático -pedagógicas, objetivo e problema de pesquisa, bem como análise e discussão dos dados coletados.

Nesse sentido, o Sistema Educacional emerge como instrumento necessário e eficaz para a construção de uma nova autopoiese dos agentes sociais, na perspectiva de serem capazes de reunir saberes necessários para o seu convívio social, tentando modificar esse quadro caótico da cultura do litígio; em outras palavras, o Sistema Educacional desponta como mecanismo apto e preventivo dos litígios sociais, evitando a movimentação da máquina judiciária. sob o prisma de que, mesmo os sistemas sendo autopoéticos, estando estruturalmente interligados, quaisquer que sejam as transformações em um deles elas afetarão, igualmente, todos os demais.

\section{O ABARROTAMENTO DO PODER JUDICIÁRIO DIANTE DAS CONTINGÊNCIAS SOCIAIS}

A ideia de um Sistema de Direito a partir da concepção luhmanniana resulta como um mecanismo de comunicação apto a reduzir a complexidade

\footnotetext{
${ }^{4}$ BRASIL. Lei 11.525 de 25 de setembro de 2007. Acrescenta $§ 5^{\circ}$ ao art. 32 da Lei n 9.394 , de 20 de dezembro de 1996, para incluir conteúdo que trate dos direitos das crianças e dos adolescentes no currículo do ensino fundamental. Disponível em:< http://www.planalto.gov.br/ccivil_03/_ato2007-2010/2007/lei//11525.htm> Acesso em 22 fev. 2018.
} 
do ambiente recorrendo-se à codificação do esquema binário lícito ou ilícito. A autopoiese do Direito é construída desde esse código e, entrementes, o Direito é analisado como um sistema que garante certa congruência aos comportamentos sociais, imunizando as sociedades de conflitos entre seus membros, visando ao desenvolvimento e à estabilidade do sistema social global.

A abstração de autopoiese remonta à teoria sociológico-jurídica da constitucionalização simbólica de Marcelo Neves, ao expressar que:

[...] autopoiese tem sua origem na teoria biológica de Maturana e Varela. Etimologicamente, a palavra deriva do grego autós (por si próprio) e poesis (criação, produção). Significa inicialmente que o respectivo sistema é construído pelos próprios componentes que ele constrói. Definem-se então os sistemas vivos como máquinas autopoiéticas: uma rede de processos de produção, transformação e destruição de componentes que, através de suas interações e transformações, regeneram e realizam continuamente essa mesma rede de processos, constituindo-a concretamente no espaço e especificando-lhe o domínio topológico. (NEVES, 1994, p. 113)

De acordo com Rodrigues e Neves (2017, p. 39-4) a autopoiese está associada à noção de feedback e de auto-organização, de tal modo que a comunicação construída em um sistema representa a informação, a realimentação e, até mesmo, a retroalimentação, trazendo implícita a formulação de circularidade operativa. Uma vez caracterizada a auto-organização e autorreferência sistêmica, concretizou-se o sentido de "autopoiésis", aferindo-se sua autoria aos biólogos chilenos Humberto Maturana e Francisco Varela (1995, 1997).

De acordo com a teoria sistêmica de Luhmann (2011), o Sistema do Direito tem por função manter estáveis as expectativas, ou seja, as normas jurídicas, que permanecem estagnadas independente de posterior violação, representam um modelo de orientação, servindo para direcionar as comunicações no Sistema Jurídico.

Para uma melhor compreensão dessas inferências, Willis Guerra Filho, um dos principais jusfilósofos do século XX, pontua que 
O sistema jurídico aparece como um dos 'sistemas funcionais' do sistema social global, com a tarefa de reduzir a complexidade do ambiente, absorvendo a contingência do comportamento social, ao garantir certa congruência entre as expectativas de como os indivíduos vão comportar-se e a generalização dessas expectativas, pela imunização do perigo de decepcionarem-se. (GUERRA FILHO, 2001, p. 186).

Assim, a comunicação jurídica faz-se necessária toda vez que há um conflito de interesses, uma controvérsia, quando a normatividade vigente pelo código da licitude deve decidir qual agente é merecedor de razão. Esse modelo de Direito como sistema autopoiético deve ser eficiente na resolução das contingências existentes nos meios ambientes sociais (ANDAKU, 2017).

Niklas Luhmann (2005, p. 359-399) sustenta que existe uma autonomia comunicativa própria no Direito, em que o sistema consegue comunicar-se com o entorno devido à autopoiese, sob o código jurídico legal/ilegal (Recht/ Unrechet) e, por ser um sistema operacionalmente fechado, produz suas próprias funções.

Com isso, demonstra-se que a autopoiese do Direito está aportada em uma ideia de fechamento operacional do sistema. Para que o Direito seja construído, é necessário que suas ações façam a diferença no entorno que torna viável sua autonomia; de sorte que o sistema do Direito passa a ser flexível, portanto mutável, diante das irritações encontradas no ambiente.

Sob tal aspecto, entende-se que o Direito atua como um mecanismo asséptico da sociedade "assim como os sistemas vivos se imunizam de seus germes" (GUERRA FILHO, 1997, p.63), tendo em vista que permite isentar os conflitos existentes nos ambientes, tentando solucionar situações imprevistas, sem, ao menos, ter conhecimento das causas que levaram às contingências, ao conflito de interesses derivado do ambiente social.

Nessa mesma toada, Tércio Ferraz Júnior salienta que o Direito passa a ser analisado por Luhmann como uma estrutura destinada a definir os limites e as interações da sociedade, com o intuito de conseguir estabilizar as expectativas nas interações e neutralizar as contingências das ações individuais do homem concreto. (FERRAZ JÚNIOR, 1980, p. 01-05). 
Contudo, a complexidade de uma sociedade como a brasileira não chega de maneira correta às periferias, sobejando ao centro, o Sistema Jurídico, encarar, volumosamente, todas as demandas, podendo gerar uma sobrecarga que provocaria o curto-circuito do sistema, na ótica de Celso Campinlongo. (VILLAS BOAS FILHO, 2017).

A organização judiciária compreende um subsistema que faz parte do epicentro do sistema do Direito. Dessa forma, todos os demais campos do Direito pertencem à periferia do Sistema, e isso garante a sua autonomia exatamente por não ter que decidir, diferenciando-se dos Tribunais que, por estarem no coração do Sistema Jurídico, são obrigados a decidir todos os casos e, quando tentam buscar o consenso, em razão da distância real das questões, a decisão transforma-se em mera ficção jurídica (LUHMANN, 2005, p. 383):

Todos os outros campos de trabalho (não judiciais) do sistema de direito pertencem à periferia. Isto é válido para as disposições normalmente designadas como "privadas", a saber: a conclusão de contratos. No entanto, também é válido para a legislação. Para a periferia não há necessidade de decidir. Nas periferias, os interesses de qualquer tipo podem ser apresentados e impostos com todos os meios disponíveis, independentemente da distinção de interesses legais / interesses ilegais. ${ }^{5}$ [tradução da autora]

Modernamente, o Conselho Nacional de Justiça (2017) apresenta a sobrecarga de litigiosidade no Brasil, alcançando cerca de 95 milhões de processos em tramitação, o que equivale a uma demanda judicial para cada dois brasileiros. (BRASIL, 2017). Por essas e outras razões, o sistema do Direito é analisado como uma máquina de solução de conflitos advindos do Sistema Social.

$\mathrm{O}$ intuito consiste em edificar aos interessados novos olhares para além do status passivo de subordinação ao Poder Judiciário, como fim único

\footnotetext{
${ }^{5}$ No original: "Todos los demás campos de trabajo (no judiciales) del sistema de derecho pertenecen a la periferia. Esto tiene validez para aquellas disposiciones que normalmente se señalan como "privadas", a saber: la conclusión de los contratos. Sin embargo es válido también para la legislación. Para la periferia no existe ninguna necesidad de decidir. En las periferias se pueden presentar intereses de cualquier índole e imponerlos con todos los medios disponibles, sin que importe la distinción de intereses legales/ intereses ilegales".
} 
para a solução das contendas sociais.

Com efeito, é inegável que a política deva ser de desjudicialização, pela prática jurídico-pedagógica nas escolas, compreendida como um mecanismo de solução de conflitos, evitando-se, consequentemente, a propositura de novas ações judiciais, tampouco o curto-circuito do Sistema Jurídico ${ }^{6}$.

\section{O SISTEMA EDUCACIONAL COMO MECANISMO DE REVERSÃO DA CULTURA DO LITÍGIO}

A legislação desempenha, mormente, a função de um órgão periférico, cabendo-lhe acomodar as irritações constantes do Sistema Jurídico pelo Sistema Político e isso somente é possível na forma de regras genericamente válidas que, por sua vez, podem ser trabalhadas no Sistema Social. Assim, irrompeu a Lei $n^{\circ} 11.525 / 2007^{7}$, que alterou a Lei de Diretrizes e Bases da Educação Nacional (LBDN), em seu artigo $32, \S 5^{\circ}$, conduzindo a alterações no Sistema Educacional, ao enfatizar a obrigatoriedade da construção do ensino -aprendizagem do ECA (Estatuto da Criança e do Adolescente) nas escolas de ensino fundamental, enquanto instrumento apto a construir a consciência ético-social dos "sócios da sociedade mundial” (GUERRA FILHO, 2015, p.80), na perspectiva de serem capazes de reunir saberes necessários para um convívio social, "para encontrarem orientação no mundo" (Idem; ibidem).

Diante disso, o ambiente escolar possui um valor diferenciado nesse cenário de implementação de ordenamentos legais. A abordagem do Estatuto da Criança e do Adolescente no Sistema Educacional é ferramenta determinante para torná-lo mais conhecido e compreendido pela pessoa em desenvolvimento, sua família e a sociedade, reduzindo, equitativamente, a complexidade

\footnotetext{
${ }^{6}$ Nesse contexto o autor Celso Campilongo ressalta que: "A complexidade de uma sociedade como a brasileira não chega de maneira correta nas periferias, sobrando para o centro encarar, de maneira bruta, todas as demandas, podendo gerar uma sobrecarga que provocaria o curto-circuito do sistema". Disponível em:< https://lutofoli.wordpress.com/2016/06/16/sociologiajuridica-aulas-finais-justica-argumentacao-juridica-acoplamentos-e-critica-a-teoria/> Acesso em 24 fev. 2018.

${ }^{7}$ BRASIL. Lei $n^{\circ} 11.525$, de 25 de setembro de 2007. Acrescenta $§ 5^{\circ}$ ao art. 32 da Lei no 9.394, de 20 de dezembro de 1996 , para incluir conteúdo que trate dos direitos das crianças e dos adolescentes no currículo do ensino fundamental. Disponível em: <https://www.planalto.gov.br/ccivil_03/_ato2007-2010/2007/lei//11525.htm> Acesso: 24 nov. 2017.
} 
da comunicação, ao tomar por base a identidade dos agentes envolvidos no fenômeno educativo e, por vezes, diante do sistema que envolve suas ações e seus discursos.

Entretanto, serão necessários esforços de todas as esferas governamentais presentes no Sistema Político para a implantação de políticas públicas de efetivação dos direitos e deveres presentes na Lei $\mathrm{n}^{\mathrm{o}} 11.525 / 2007$, fato que não tem ocorrido até agora, com mais de nove anos de vigência dessa legislação (POZZOLI; GIMENEZ, 2012, p.85).

A falta de um projeto que contemple aspectos de cidadania e inclusão social nos ambientes escolares de ensino fundamental afeta, diretamente, a qualidade de vinculação da criança e do adolescente com o aprendizado e também sua trajetória ético-social diante do Sistema Social.

As escolas devem incluir, em seu projeto educativo, a construção da identidade moral, apresentando possibilidades de inserção social na formação cidadã da pessoa em desenvolvimento, não servindo apenas de espaço de replicação de conteúdo.

Ocorre que, para a educação estatutária processar-se, de fato, nos ambientes escolares, é preciso se conjugar, necessariamente, três elementos: os sentidos de informar, de comunicar e de entender (LUHMANN, 2011, p. 301); de outra forma: o professor deve buscar entender se foi realmente compreendido, numa lógica de comunicação.

Segundo Luhmann, a função dos meios de comunicação consiste em orquestrar a auto-observação do sistema social, em tornar as coisas conhecidas. Enfatiza, ainda, que as unidades elementares da sociedade são as comunicações; as pessoas são analisadas como construções sociais (LUHMANN, 2005, p. 158).

Logo, sendo a criança e o adolescente seres ativos na realidade que os cercam, é imprescindível que a educação que constroem na escola seja rica de propósitos, atitudes, regras e valores éticos, a fim de que lhes seja facultado construir suas personalidades, frutos de uma reorientação autopoiética. A educação, além de ser um direito de todos, não pode ser limitada apenas aos cálculos, à leitura e à escrita; é premente que sirva como importante meio de aquisição de valores morais e, por vezes, de seu exercício, para que haja a ne- 
cessária adaptação à vida social (PIAGET, 1973, p.40).

Conjuntamente aos avanços sociais, diversos conflitos emergiram, e a educação escolar, por seu turno, é analisada como mecanismo de aprimoramento das potencialidades do indivíduo, para a formação de valores que viabilizem a convivência harmônica com o semelhante, na busca do bem-estar social. "[...] O bom senso leva-nos a crer que, se a sociedade muda, a escola tem de evoluir junto com ela, antecipar e até inspirar transformações culturais (PERRENOUD, 2002, p.190)".

Nesse sentido, um dos aspectos relegados a um segundo plano pelas políticas públicas do ensino fundamental é a dificuldade de inserção da pessoa em desenvolvimento no sistema social, o que tem produzido um cenário de inviabilidade de formação cidadã e impossibilidade da construção de um projeto ético-social. As ações de orientações éticas, nesse horizonte, têm sido apenas pontuais e de alcance restrito. A escola advém como um espaço ideal para ações que visem a levar a criança e o adolescente a refletirem sobre as questões éticas, morais, construindo, apensa aos educandos, uma nova autopoiese social.

A criança e o adolescente pertencentes à coletividade necessitam ser orientados como seres humanos no Sistema Social. Ressalta-se o importante papel da escola para a construção de uma educação cidadã unificada ao aprendiz, para que este possa desenvolver-se como pessoa humana e desempenhar seu papel na esfera social.

Maritain (1968, p. 42) destaca o essencial objetivo da educação:

É, pois, evidente que a educação do homem deve preocupar-se com o grupo social e preparar a criança para desempenhar nele seu papel. Formar o homem para uma vida normal, útil e devotada na comunidade, ou orientar o desenvolvimento da pessoa humana na esfera social, despertando e fortificando o senso de sua liberdade, como o de suas obrigações e responsabilidades, constitui o objetivo essencial da educação.

Faz-se necessário o desenvolvimento de um novo modelo de orientação ético-social a ser implantado na educação escolar, conforme Lei $n^{\circ}$ 
11.525/2007, levando-se em conta a especificidade da população, das características e da formação do ser social qualificado a integrar-se no coletivo. E, ao se referir ao público infanto-juvenil, a criança e o adolescente necessitam ser conhecedores de seus direitos e de seus deveres para que possam efetivá-los em sua integridade, tornando-se adultos habilitados a praticar ações políticosociais adequadas ao Sistema Social.

Aliás, a Lei de Introdução às Normas de Direito Brasileiro (LINDB) contém, em seu artigo $3^{\circ}$, a presunção de que todos conhecem as leis e, consequentemente, não se pode alegar desconhecimento com o fito de justificar a prática de condutas ilegais.

O fato é que uma incoerência prepondera, tendo em vista que muitos perpetram atos ilícitos sem terem ciência e consciência da ilegalidade de suas condutas, acarretando demandas judiciais desnecessárias. Consequentemente, por meio da educação dos direitos e dos deveres às pessoas em formação, poder-se-á reverter a extrema judicialização que se mostra insuficiente para atender as contingências presentes nos ambientes sociais.

É imperioso, pois, que se impulsione a construção do ensino e da aprendizagem do diploma estatutário nas instituições escolares, primeiro para a sua compreensão e, segundo, para a redução das práticas de atos ilícitos.

Sendo assim, o ensino sobre o Estatuto da Criança e do Adolescente nas escolas de ensino fundamental avulta a preocupação com a integridade ético-social da pessoa em formação. Nesse ínterim, destaca-se que, a escola deve contar com profissionais capacitados e especializados, afirmando que essa formação deve se dar em ambientes acadêmicos e institucionais especializados para o desenvolvimento de uma ação educativa eficaz. Os direitos e as garantias que o Estatuto da Criança e do Adolescente acolhe, normativamente, são instrumentos e veículos de cidadania responsável, garantidores da dignidade e felicidade dos cidadãos, não podendo ficar vinculados somente às intenções do Estado e às intenções do legislador (GIACÓIA, 2012, p. 30-43).

Na concepção de Häberle (2002, p. 123), o respeito à dignidade consiste na oferta de oportunidades e proteção às minorias, sendo essa a verdadeira essência de um Estado Constitucional de Direitos: 
Hoje, a partir da plataforma oferecida pela constituição pluralista, procede apenas falar, portanto, em Estado de Direito, na medida em que este proporciona uma adequada proteção às minorias. Essa proteção começa pela consecução de determinados objetos educacionais, como 'a tolerância' e o respeito da 'dignidade do outro ${ }^{8}$. [tradução da autora]

Ao contemplar o respeito à dignidade das minorias, incluindo os direitos e as garantias adquiridos nos ordenamentos jurídicos destinados à proteção do público infanto-juvenil, o grande desafio está em concorrer para a formação de um Estado Democrático de Direito, que não se omite diante das necessidades sociais, mas que se proponha a promover e salvaguardar as legítimas aspirações das crianças e dos adolescentes, defendendo sua dignidade enquanto ser individual e social.

Para Paulo Freire (2000, p. 67),

Não é possível refazer este país, democratizá-lo, humanizá -lo, torná-lo sério, com adolescentes brincando de matar gente, ofendendo a vida, destruindo o sonho, inviabilizando o amor. Se a educação sozinha não transformar a sociedade, sem ela, tampouco a sociedade muda.

A disciplina sobre a ética cidadã, disposta nos ementários legais, não pode ser tratada nos currículos escolares apenas como tema transversal; antes, é primordial que figure como matéria própria, presente na matriz curricular e construída no dia a dia do ambiente escolar, uma verdadeira possibilidade de troca concreta para atingir, efetivamente, a comunicação.

A educação cidadã ofertada nos ambientes escolares do ensino fundamental reivindica ser a semente de possibilidades para a transformação social e, consequentemente, a reversão da cultura do litígio.

\footnotetext{
${ }^{8}$ No original: "Hoy por hoy, desde la plataforma que ofrece la constitución pluralista, tan solo procede hablar, por tanto, Del Estado constitucional em la medida em que este proporciona uma adecuada protección de las minorias. Dicha protección comienza por la consecución de determinados objetos educacionales, como 'la tolerância' y el respeto de la 'dignidad del outro' [...]”'
} 


\section{O ESTATUTO DA CRIANÇA E DO ADOLESCENTE NO AMBIENTE ESCOLAR PARA A CONSTRUÇÃO DE UMA NOVA AUTOPOIESE ÉTICO-SOCIAL}

A análise em apreço derivou de coleta de dados empreendida ao longo do ano letivo de 2016, tendo como protagonistas e partícipes 26 estudantes (com idades entre 08 e 09 anos), integrantes de uma turma do terceiro ano do ensino fundamental de uma escola pública municipal, localizada na região central do município de Vera Cruz, interior do Estado de São Paulo, Brasil. Quanto à classe socioeconômica do alunado regularmente matriculado na unidade escolar em questão, a pluralidade revela-se estremada, essencialmente, na média baixa.

As investigações e intervenções ora engendradas foram motivadas por uma desconfortável indagação: Em quais aspectos o estudo do ECA, em sala de aula, pode contribuir para a formação cidadã de estudantes do ensino fundamental? Tendo em vista consignada inquietação, o objetivo geral da presente pesquisa convencionou-se, então, em promover atividades educacionais relacionadas ao Estatuto da Criança e do Adolescente para crianças de tal etapa da escolarização (o ensino fundamental), avaliando conhecimentos, comportamentos e atitudes anteriores e posteriores à formação do educando.

Para tanto, optou-se pela abordagem metodológica qualitativa caracterizada pelo "[...] contato direto e prolongado do pesquisador com o ambiente e a situação que está sendo investigada, via de regra através do trabalho intensivo de campo", sendo que "[...] o 'significado' que as pessoas dão às coisas e à sua vida são focos de atenção especial pelo pesquisador (LÜDKE; ANDRE, 1986, p. 11-12)".

Os métodos de coleta de dados incluíram, desta feita, a observação e o registro; já a análise dos dados ocorreu por meio de categorias descritivas. Questionários com perguntas abertas também foram aplicados como fonte de compreensibilidade e de conhecimento do conteúdo exposto.

Destarte, os dois primeiros meses do ano letivo foram dedicados a observações das características gerais da turma e, também, apreciações e registros das particularidades de cada aluno, incluindo o histórico familiar, para que fosse possível pensar em atividades adequadas de intervenção.

Como estratégia didático-pedagógica, a ênfase repousou em: aulas 
expositivas dialogadas, dinâmicas em grupo, atividades lúdicas e lições de casa, ações que favorecessem aos conteúdos serem também compartilhados com as famílias. Já quanto às discussões metodológicas, ou seja, sobre a forma como os conteúdos relacionados aos direitos e aos deveres podem ser construídos em sala de aula, parece haver um consenso na literatura de que não se trata de tornar o referido tema uma disciplina ou, mesmo, reservar aulas/ momentos exclusivamente aos direitos humanos. Sobre a questão, contemporizam Benevides (2003, p. 309-318), Carvalho (2004, p. 332), Genevois (2017, p. 1) e Sacavino (2000, p. 36-48), partindo do princípio de que a educação estatutária deve resultar de todas as vivências cotidianas e de todos os atos desencadeados no dia a dia escolar.

Observa-se que se trata de uma discussão complexa que não se encerra com a mera defesa de uma ou outra opção metodológica; longe disso, alberga um debate que se enriquece consoante o diálogo e a reflexão sobre a prática. Em outras palavras, não basta que uma ou outra opção metodológica seja, fielmente, defendida sem que se tenha atestado eficácia na concretude das relações escolares, considerando as diferentes realidades educacionais presentes no país. Nessas condições, por conta das especificidades do Sistema Educacional do Estado de São Paulo, bem como pelas especificidades da turma, optou-se, enfim, pela abordagem transversal.

O próximo passo consistiu em analisar o índice temático ${ }^{9}$ da edição revisada e atualizada do ECA distribuída pelo Governo do Estado de São Paulo (SÃO PAULO, 2012), selecionando os temas mais significativos a serem trabalhados com a turma; a saber: alcoólatras e toxicômanos, atendimento, ato infracional, comunidade, conselho Tutelar, criança, crimes contra a criança e o adolescente, cultura, dever, diversões, educação, exploração e abuso sexual, família, guarda, lazer, profissionalização, saúde e vida. Além disso, empregou-se a Parte Geral (Livro I) ${ }^{10}$

${ }^{9}$ O índice temático organiza em temas os diversos artigos e parágrafos da Lei $n^{\circ} 8.069$, de 13 de julho de 1990, que institui 0 Estatuto da Criança e do Adolescente. Para consultar o índice completo, ver: São Paulo (2012).

${ }^{10} \mathrm{O}$ Estatuto é constituído de dois livros. O Livro I autodenomina-se Parte Geral e contém títulos que versam sobre a criança e o adolescente como sujeitos fundamentais e individuais que devem ser assegurados com absoluta prioridade por toda a sociedade e pelo poder público. O segundo livro (Livro II ou Parte Especial) contém artigos que abordam as políticas de atendimento, as medidas de proteção, prática do ato infracional, responsabilidades dos pais ou responsáveis e o Conselho Tutelar, entre outras. 
do ECA como embasamento para as atividades desenvolvidas. Para cada eixo temático, foram preparadas, em média, dez atividades, de forma que as discussões pudessem ocorrer diariamente.

Uma vez que o ECA regulamenta medidas de proteção no tocante ao tema alcoólatras e toxicômanos, e por haver na turma uma criança enfrentando problemas relacionados a esse conteúdo, foram desencadeadas discussões problematizadoras, com urgência, no decurso das práticas deste eixo temático, juntamente com o uso de histórias em quadrinhos, desenhos e interpretações textuais.

Quanto ao tema atendimento, a lei apresenta disposições gerais sobre a política de atendimento dos direitos da criança e do adolescente, com a presença de linhas de ação e diretrizes. Por meio de estratégias didático-pedagógicas dialógicas e participativas, pautadas em princípios democráticos, trabalhou-se o conceito de cidadania plena ${ }^{11}$ com as crianças, possibilitando o discernimento de que é responsabilidade do Estado prover direitos, cabendo aos cidadãos lutar por eles, engajando-se em sua efetivação. As ações envolveram, também, a conscientização sobre a importância de cada pessoa na luta pelo bem-estar coletivo, mesmo diante das diferenças que caracterizam o ser humano.

Ao trabalhar o ato infracional, em virtude da escolha pela abordagem transversal, diferentes áreas do conhecimento estiveram presentes (no caso, a história, a matemática, a língua portuguesa e a arte), ensejando discutir sobre regras de conduta, ética e comportamento em sociedade. A fim de despertar nas crianças alguns sentimentos que levam ao desenvolvimento de valores como o respeito, a tolerância, a solidariedade - foram realizadas dinâmicas e brincadeiras. Do mesmo modo, foram discutidas as consequências de atos que violam as regras sociais, visando a preveni-los.

No geral, as práticas foram programadas estribadas nos Títulos I, II e III do primeiro livro do Estatuto da Criança e do Adolescente, os quais dis-

\footnotetext{
${ }^{11}$ A ideia de cidadania explicitada neste texto está em consonância com a perspectiva de Candau et al. (2013), para quem exercer a cidadania plena significa afirmar a necessidade de um processo contínuo de revisão das políticas públicas e de melhoria nas condições culturais, materiais, sociais e políticas, também pressupondo a participação ativa dos sujeitos de direitos. Tais, por sua vez, devem ser formados no sentido de conhecer e lutar constantemente pelos seus direitos.
} 
põem sobre o direito à vida, saúde, liberdade, dignidade, informação, cultura, lazer; o direito aos esportes, às diversões, à educação, entre outros direitos básicos de todo ser humano.

Como forma de avaliação, as crianças, bem como seus pais ou responsáveis, responderam a um pequeno questionário dotado de perguntas abertas e de um significativo espaço para respostas. A observação e o registro contínuo de atitudes e comportamentos no espaço escolar identicamente contribuíram para a análise dos resultados, em tópico a ser contemplado com maior alcance na continuidade deste estudo.

Tendo em vista a problemática e o propósito que motivaram e nortearam esta investigação, as crianças responderam a um questionário composto por três questões abertas, cujas respostas foram organizadas em categorias, conforme sua frequência, como corroborado nos gráficos a seguir. Dentre as três perguntas, duas delas permitiram respostas amplas. $\mathrm{O}$ objetivo da primeira pergunta foi constatar os conhecimentos prévios que as crianças traziam sobre o Estatuto da Criança e do Adolescente, comparando-os com as respostas das questões posteriores. No entanto, para a surpresa da pesquisadora, das 26 crianças, apenas uma já ouvira sobre o ECA, embora ignorasse seu conteúdo, distinguindo somente sua existência:

\section{GRÁFICO 1 - CONHECIMENTOS PRÉVIOS SOBRE O ECA}

\section{Pergunta 1: "O que você sabia sobre o ECA antes das aulas?"}

[NOME DA

CATEGORIA]

[PORCENTAGEM]

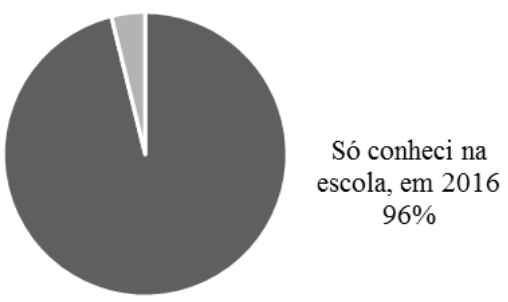

FONTE: ELABORADO POR MELISSA ZANI GIMENEZ

As respostas à segunda pergunta foram amplas e permitiram a organização em cinco categorias, conforme o gráfico: 


\section{GRÁFICO 2 - OPINIÃO SOBRE A UTILIDADE DO ECA}

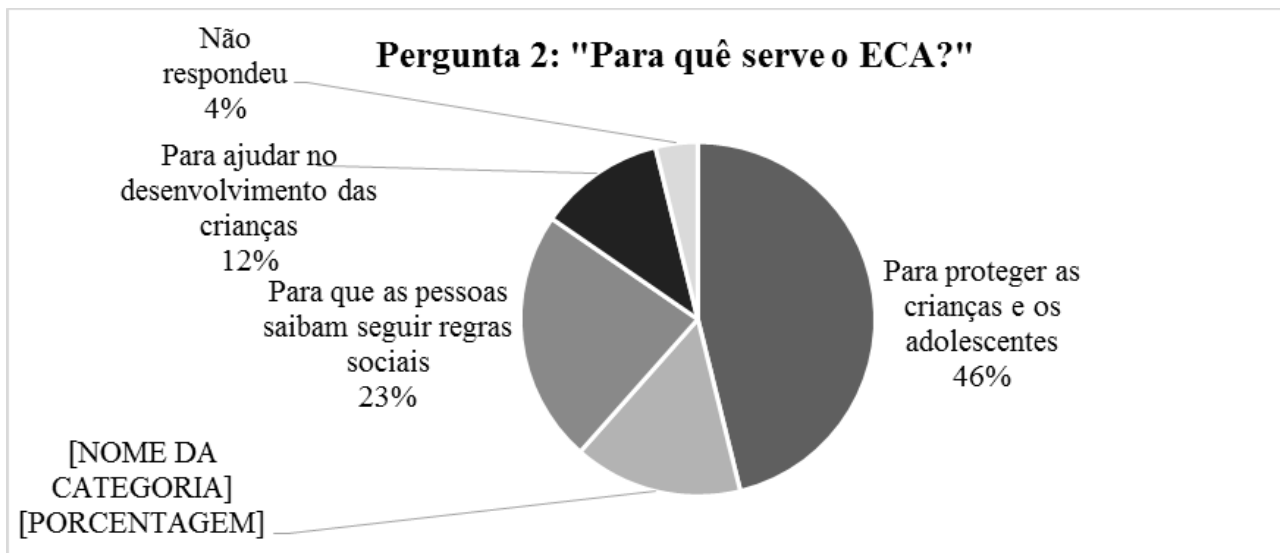

FONTE: ELABORADO POR MELISSA ZANI GIMENEZ

À luz das informações reunidas, observou-se que a maioria das crianças se apropriou do Estatuto da Criança e do Adolescente na qualidade de um mecanismo de defesa; por outro lado, a análise dos registros realizados no caderno de campo da pesquisadora serviu como meio para se evidenciar aspectos importantes no que concerne à conscientização e ao encorajamento para tomada de atitudes por parte das crianças e das famílias.

Concebendo o diploma estatutário como um meio de proteção, a criança que se encontrava sujeita à situação vulnerabilidade em razão da contingência de alcoolismo na família sentiu-se segura para conversar com a escola e, então, orientarse. Cumpridos os procedimentos regulares, dias após, em consonância com a prescrição da Lei $n^{\circ} 8.069 / 1990$, que, em seu art. 129, inciso II, determina que a pessoa com dependência do álcool seja encaminhada para programa oficial de auxílio, orientação e tratamento, conseguiu-se, também por meios legais, o afastamento temporário do convívio da criança com o dependente. Além desse, outro caso foi detectado no final do ano de 2016, após o desenvolvimento das atividades, quando outra das crianças encorajou-se a relatar situações sofridas de violência sexual. $\mathrm{Na}$ oportunidade, houve o devido apoio da escola e do Conselho Tutelar; quanto às medidas legais em atendimento ao caso estas encontram-se em andamento.

O estudo salienta que o conhecimento da lei e, sobretudo, a informação sobre o que é uma lei mobilizou as crianças e seus responsáveis para 
o desenvolvimento de ações que desencadearam melhorias em suas vidas. $\mathrm{O}$ conhecimento sobre o amparo que proporciona o plano legal pode evitar e, mesmo, cessar situações de atrocidades contra crianças, como a pedofilia e a violência; consequentemente, houve a reversão da cultura do litígio, tendo em vista que uma nova autopoiese foi construída.

Os dados também destacaram as questões morais e éticas presentes nas atividades relacionas ao Estatuto da Criança e do Adolescente durante o ano letivo. Como se observa, $23 \%$ das respostas referem-se a regras sociais e $15 \%$ fizeram referência ao respeito, bem-estar coletivo, solidariedade, amizade e tolerância.

As respostas coletadas na terceira pergunta permitiram a classificação dos dados em três categorias:

\section{GRÁFICO 3 - O QUE FOI POSSÍVEL APRENDER A PARTIR DO ECA}

\section{Pergunta 3: "O que você aprendeu com as atividades sobre o ECA?"}

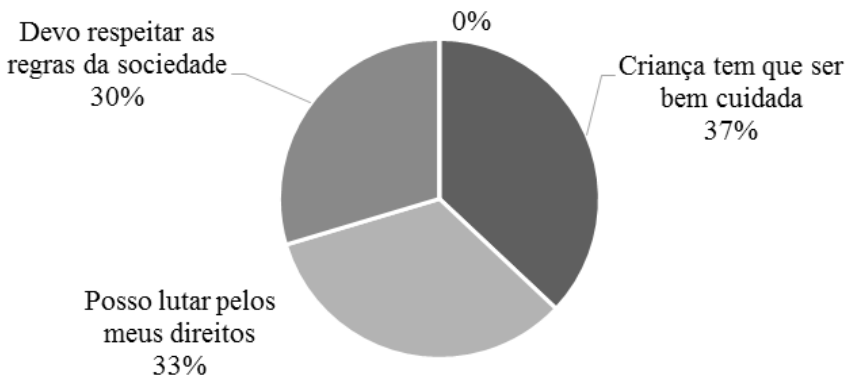

FONTE: ELABORADO POR MELISSA ZANI GIMENEZ

As categorias aventadas nesta questão se aproximam das categorias anteriores, ou seja, a concepção sobre o Estatuto da Criança e do Adolescente desenvolvida nas crianças inclui aspectos morais, éticos, encorajamento e conscientização sobre os meios de proteção legal. É interessante ponderar que os três grupos possuem frequências muito próximas, com as opiniões transitando, quase que de maneira igualitária, entre "regras sociais", "mecanismo de defesa" e "luta por direitos".

As observações e registros contínuos corroboram os dados. Por meio 
deles, foi possível constatar características iniciais de relacionamento entre as crianças: muitas brigas, palavras de ofensas (inclusive direcionadas à professora); inúmeras crianças com baixa autoestima e outras tantas com dificuldades para se expressar, seja na fala em público seja na expressão de sentimentos. No final do ano letivo, a mudança no relacionamento entre as crianças e entre as crianças e a professora tornou-se nítida. As brigas passaram a ser bem menos frequentes, sendo deveras importante enfatizar que as demais crianças, aquelas que não estavam envolvidas nos eventuais conflitos, de sua parte, estas tentavam realizar mediações com base nos conhecimentos adquiridos no decurso das aulas. Ademais, as crianças passaram, também, a dirigirem-se com maior respeito em relação à professora e demais funcionários da escola.

Na busca por informações, outro questionário com duas perguntas abertas foi enviado para que as crianças respondessem, juntamente com seus pais ou responsáveis. Sobre a primeira questão, analisa-se:

\section{GRÁFICO 4 - OPINIÃO SOBRE AS AULAS PAUTADAS NO ECA}

\section{Pergunta 4: "O que você tem a dizer sobre as aulas planejadas a} partir do ECA?"

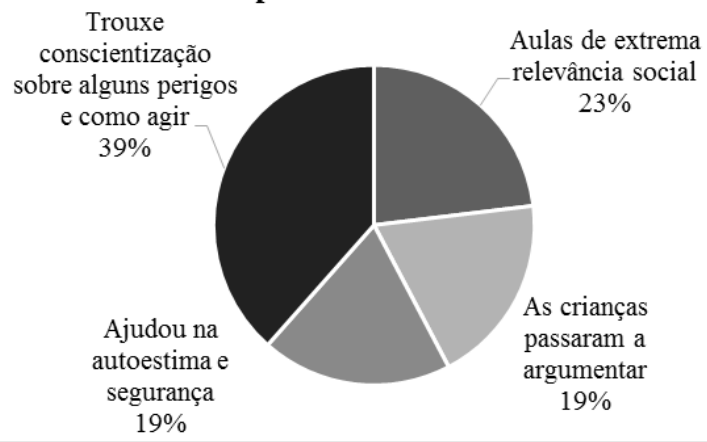

FONTE: ELABORADO POR MELISSA ZANI GIMENEZ

Quatro categorias foram criadas com fundamento na frequência das respostas. Os registros em caderno de campo também constataram melhorias quanto à autoestima, segurança e argumentação. Dessa forma, pode-se afirmar que os benefícios propiciados pelas aulas sobre o Estatuto da Criança e do Adolescente estenderam-se, também, para as relações familiares. Os dados revelam, ainda, que o trabalho com a Lei n. 8.069/1990 permite que os funda- 
mentos da formação de sujeito de direitos ${ }^{12}$ - já mencionado neste texto - sejam colocados em ação.

Durante as discussões desencadeadas ao longo do ano letivo, constatou-se que as crianças e suas famílias possuíam uma ideia pejorativa quanto à atuação do Conselho Tutelar. À vista disso, a última das perguntas apresentadas foi elaborada, precisamente, com a intenção de verificar se houve (ou não) mudança de tal pensamento. Para tanto, apenas duas categorias foram propostas desde as respostas:

\section{GRÁFICO 5 - OPINIÃO SOBRE A PARCERIA ESCOLA-FAMÍLIA-CONSELHO TUTELAR}

\section{Pergunta 5: "O que você pensa sobre a parceria entre a escola, a família e o Conselho Tutelar?"}

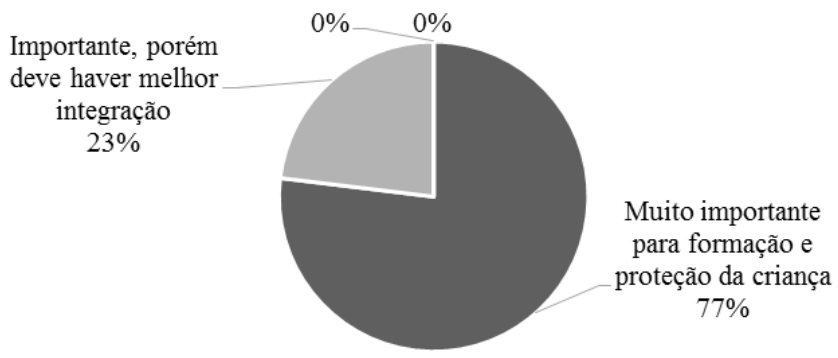

FONTE: ELABORADO POR MELISSA ZANI GIMENEZ

A percepção pejorativa deve-se ao fato de que muitas escolas referenciam, erroneamente, o Conselho Tutelar para ameaçar as crianças ou as famílias, salientando que a atuação principal do Conselho compreende o afastamento da criança daqueles/as que possuem sua tutela ou guarda. Porém, ao trabalhar o verdadeiro sentido do Conselho Tutelar com as crianças e as famílias, testemunha-se, por meio dos dados efetivos, que as respostas foram para além da mudança de concepção. Com isso, $23 \%$ dos pais ou responsáveis fizeram sugestões, alegando a necessidade de se haver melhor integração entre

\footnotetext{
${ }^{12}$ Retomando, são quatro os movimentos que compõem a formação de sujeito de direitos, conforme Candau et al. (2013): "[...] saber/conhecer os direitos; desenvolvimento de uma autoestima positiva; promoção da capacidade argumentativa; e ser um(a) cidadão(ã) ativo(a) e participativo(a)".
} 
a escola, as famílias e o Conselho Tutelar, incluindo reuniões e planejamento de ações em prol da infância no município.

Outrossim, o estudo do Estatuto da Criança e do Adolescente na sala de aula refletiu na participação das famílias em reuniões escolares e na frequência das crianças na escola. Assim, registrou-se $98 \%$ de presença na Caderneta Escolar, considerando todo o ano letivo e 100\% de presença nas duas últimas reuniões de pais ou responsáveis, realizadas nos meses de agosto e novembro de 2016.

Nesse quadro, pode-se concluir que todo o Sistema Social e, em especial, o Sistema Educacional são movidos e alimentados pela comunicação. No caso dos alunos do ensino fundamental, um verdadeiro diálogo e a sintonia de comunicações foram efetivados, construindo uma nova autopoiese social, novas observações ético-sociais e, por vezes, a solução das contingências sociais mediada pela educação, ocasionando, em síntese, a diminuição de novas demandas judiciais.

\section{CONSIDERAÇÕES FINAIS}

A Pós-Modernidade acarretou múltiplas contingências e conflitos no Sistema Social e, nesse ínterim, o Sistema Jurídico, por estar no centro do Sistema de Direito, é analisado como uma máquina de solução de conflitos, ocasionando o abarrotamento de processos, a lentidão judiciária e, por vezes, o seu curto-circuito, tendo em vista o fato de ser analisado como fim único de solução das demandas sociais.

Também a educação ético-social nos ambientes escolares é esquadrinhada como mecanismo de aprimoramento das potencialidades do indivíduo, para a formação de valores que possibilitam a convivência harmônica com o semelhante, na busca do bem-estar social.

Uma disciplina que descortine os ensinamentos do Estatuto da Criança e do Adolescente (ECA), ao ser inserida nos currículos escolares em conformidade com a Lei $\mathrm{n}^{\mathrm{o}} 11.525 / 2007$, não pode ser convencionada aos currículos escolares apenas como tema transversal; ao contrário disso, constitui matéria própria, devendo estar presente na matriz curricular e ser construída no dia 
a dia do ambiente escolar, enquanto uma verdadeira possibilidade de troca concreta para atingir, de fato, a comunicação.

A criança e o adolescente, por serem pessoas em desenvolvimento, necessitam ser conhecedores de seus direitos e de seus deveres, para que possam efetivá-los em sua integridade, tornando-se adultos capazes de praticar ações político-sociais adequadas ao Sistema Social.

Dessa forma, é evocada a necessidade da educação ético-social estar presente nos bancos escolares, conforme fez jus a pesquisa escolar, por meio de fluxos de comunicação adequados e, efetivamente, compreendidos pelos alunos, determinantes de uma reorientação autopoiética e aptas a reverter a cultura do litígio.

Os resultados da pesquisa permitem concluir que a construção da educação ético-social no Sistema Educacional, pautada no ensino-aprendizagem do diploma estatutário, em âmbito escolar, além de se tratar de uma obrigação prevista em lei, pode desencadear mudanças relacionadas à autoestima, segurança, expressão oral, mudanças de atitudes, comportamentos, relacionamentos e, também, mudanças de concepções, sendo capaz, enfim, de proporcionar uma nova autopoiese social.

Destaca-se, entretanto, que os conhecimentos concernentes aos direitos infantoadolescentes precisam estar presentes, cotidianamente, no ambiente escolar para que as pessoas em desenvolvimento possam obter novas observações de ações e de seus discursos, justificando a assertiva de que o sistema social é resultado sistêmico de comunicações.

A mudança de paradigma (da Doutrina da Situação Irregular para a da Doutrina da Proteção Integral), no entanto, por si só, não é suficiente para que os direitos das crianças sejam protegidos. Conforme menciona a própria lei, é dever da sociedade, de modo geral, assegurar a efetivação de direitos básicos. E, a escola, enquanto um braço dos mais importantes dos Sistemas Sociais, não deve trabalhar nesta perspectiva apenas porque determina a lei, mas, sobretudo, porque possui uma responsabilidade social.

Finalmente, o Sistema Educacional insere-se como instrumento necessário para a construção da consciência ético-social dos "sócios da sociedade mundial", sendo capazes de reunir saberes indispensáveis para o seu convívio 
social; retroagindo esse quadro caótico da cultura do litígio. Mesmo porque, mesmo sendo sistemas autônomos, autopoiéticos, delineiam-se, também, estruturalmente acoplados e, no caso, as transformações em um deles são suficientes para afetar igualmente aos demais.

\section{REFERÊNCIAS}

AFFONSO, D.; SEDREZ, M. L. da C. Introdução: Educar em direitos humanos: Um desafio. In: VIOLA, S. E. A.; ALBUQUERQUE, M. Z de. (Orgs.). Fundamentos para Educação em Direitos Humanos. São Leopoldo: Sinodal/EST, 2011.

AMARAL E SILVA, A. F. A criança e o adolescente em conflito com a lei. Florianópolis, Conselho Estadual dos Direitos da Criança e do Adolescente, 1998.

ANDAKU, Juliana Almenara. O Direito na teoria de Niklas Luhmann. Disponível em: <file:///C:/Users/Mel/Downloads/01_-_o_direito_na_teoria_de_niklas_ luhmann.pdf>. Acesso em: 21 nov. 2017.

AQUINO, J.; ARAÚJO, F. Direitos humanos na sala de aula: a ética como tema transversal. São Paulo: Moderna, 2001.

ASSIS, O. Q. O estoicismo e o direito: justiça, liberdade e poder. São Paulo: Lumen Juris, 2002.

BAZÍLIO, L. C. Avaliando a implantação do Estatuto da Criança e do Adolescente. In: BAZÍLIO, L. C.; KRAMER, S. Infância, educação e direitos humanos. 4. ed. São Paulo: Cortez, 2011, p. 23-34.

BENEVIDES, M. V. Educação em direitos humanos: de que se trata? In: BARBOSA, R. L. L. B. (Org.). Formação de educadores: desafios e perspectivas. São Paulo: Editora UNESP, 2003, p. 309-318.

BOBBIO, N. A era dos direitos. Rio de Janeiro: Campus, 1992.

BRASIL. Constituição da República Federativa do Brasil de 1988. Brasília, DF: Senado Federal: Centro Gráfico, 1988. Disponível em:

<http://www.planalto.gov.br/ccivil_03/_Ato2007-2010/2007/Lei/L11525.htm>. Acesso em: 11 fev. 2017. 
Lei n ${ }^{0}$ 8.069, de 13 de julho de 1990. Dispõe sobre o Estatuto da Criança e do Adolescente e dá outras providências. Disponível em:

<http:/ / www.planalto.gov.br/ccivil_03/leis/L8069.htm>. Acesso em: 11 fev. 2017.

Lei $\mathbf{n}^{\mathbf{0}}$ 11.525, de 25 de setembro de 2007. Acrescenta $\S 5^{\circ}$ ao art. 32 da Lei no 9.394, de 20 de dezembro de 1996, para incluir conteúdo que trate dos direitos das crianças e dos adolescentes no currículo do ensino fundamental. Disponível em:

<http:/ / www.planalto.gov.br/ccivil_03/_Ato2007-2010/2007/Lei/L11525.htm>. Acesso em: 11 fev. 2017.

Resolução $\mathbf{n}^{\mathbf{0}}$ 1, de 30 de maio de 2012. Estabelece Diretrizes Nacionais para a Educação em Direitos Humanos. Disponível em: <http:/ / portal.mec.gov.br/ index.php?option=com_docman\&view=download\&alias=10889-rcp001-12\&category_slug=maio-2012-pdf\&Itemid=30192>. Acesso em: 11 fev. 2017.

Conselho Nacional de Justiça. Dados estatísticos. Disponível em: <http:/ / www.cnj.jus.br/programas-e-acoes/politica-nacional-de-priorizacao-do-1-graude-jurisdicao/dados-estatisticos-priorizacao>. Acesso em: 24 nov. 2017.

Lei 11.525 de 25 de setembro de 2007. Acrescenta $\S 5^{\circ}$ ao art. 32 da Lei $\mathrm{n}^{\circ}$ 9.394, de 20 de dezembro de 1996, para incluir conteúdo que trate dos direitos das crianças e dos adolescentes no currículo do ensino fundamental. Disponível em: < https:/ / www.planalto.gov.br/ccivil_03/_ato2007-2010/2007/lei/111525.htm>. Acesso em: 24 nov. 2017.

CANDAU, V. M. Educação em direitos humanos: desafios atuais. In: SILVEIRA, M. G. et al. (Org.). Educação em direitos humanos: fundamentos teórico-metodológicos. Joao Pessoa: Editora Universitária, 2007, p. 399-412.

. Educação em direitos humanos e formação de professores. In: SACAVINO, S.; CANDAU, V. M. (Org.). Educação em direitos humanos: temas, questões e propostas. Rio de Janeiro: DP et Alli Editora, 2008, p.73-92.

et al. Educação em Direitos Humanos e formação de professores(as). 1. ed. São Paulo: Cortez, 2013.

CARVALHO, J. S. et al. Formação de professores e educação em direitos humanos e cidadania: dos conceitos às ações. In: CARVALHO, J. S. (Org.). Educação, cidadania e direitos humanos. Petrópolis: Vozes, 2004.

CARVALHO, J. S. Podem a ética e a cidadania ser ensinadas? In: CARVALHO, J. S. (Org.). Educação, cidadania e direitos humanos. Petrópolis: Vozes, 2004.

FERRAZ JÚNIOR, Tércio Sampaio. In: Niklas Luhmann. Legitimação pelo Procedimento. Tradução de Maria da Conceição Côrte Real. Brasília: Editora Universidade de Brasília, 1980. 
FORTES, E. Apresentação. In: TAVARES, C.; SILVA, A. M. M. (Org.). Políticas e fundamentos da educação em direitos humanos. São Paulo: Cortez, 2010.

FREIRE, Paulo. Pedagogia da Indignação: cartas pedagógicas e outros escritos. São Paulo: UNESP, 2000.

GENEVOIS, M. P. Educação e direitos humanos. 2007. Disponível em: <http:// www.dhnet.org.br/inedex.htm>. Acesso em: 06 jan. 2017.

GIACÓIA JÚNIOR. Oswaldo. Princípios e interpretação do ECA. In: NAHAS, Thereza Christina; GENOVA, Jairo José; SILVA, Nelson Finotti (Orgs.). ECA: efetividade e aplicação. São Paulo: LTr, 2012.

GIMENEZ, Melissa Zani. Cultura da cidadania no ensino fundamental - apontamentos sobre a (in)efetividade do Estatuto da Criança e do Adolescente: uma construção do saber jurídico. 2014. 179 f. Dissertação (Mestrado em Direito). Fundação de Ensino "Eurípides Soares da Rocha", mantenedora do Centro Universitário Eurípides de Marília - UNIVEM, Marília, 2014.

GUERRA FILHO, Willis Santiago. In: A SOCIEDADE DA SOCIEDADE MUNDIAL. Revista Brasileira de Sociologia do Direito, Porto Alegre, ABraSD, v. 2, n. 1, p. 7484, jan./jun., 2015.

Teoria da ciência jurídica. São Paulo: Saraiva, 2001.

Autopoiese do direito na sociedade pós-moderna: introdução a uma teoria sistêmica. Porto Alegre: Livraria do Advogado, 1997.

HÄBERLE, Peter. Pluralismo y Constitución: estudos de teoría constitucional de la sociedad abierta. Tradução de Emilio Mikunda. Madrid: Editorial Tecnos, 2002.

HORTA, M. M. R. Educar em direitos humanos: compromisso com a vida. In: CANDAU, V. M.; SACAVINO, S. (Org.). Educar em direitos humanos: construir democracia. Rio de Janeiro: DP\&A, 2000.

KRAMER, S. Política do Pré-escolar no Brasil: a arte do disfarce. 7. ed. São Paulo: Cortez, 2003.

LOBÃO, N. Relatório sobre o Projeto de Lei n ${ }^{0}$ 5705, de 2005. Brasília DF: Comissão de Educação e Cultura, 2007. Disponível em: <http:/ / www.camara.gov.br/proposicoesWeb/prop_mostrarintegra?codteor $=457018 \&$ file $\% 20$ name $=\% 20 \mathrm{PRL}+1+\% 20$ CEC+\%3D\%3E+PL+5705/2005>. Acesso em: 11 fev. 2017. 
LUHMANN, Nilklas. El derecho de la sociedade. Traducción: Javier Torres Nafarrate, com la colaboración de Brunhilde eker, Silvia Pappe y Luis Felipe Segura. México: Iberoamericana, 2005.

A realidade dos meios de comunicação. Trad. de Ciro Marcondes Filho. São Paulo: Paulus, 2005.

Introdução à teoria dos sistemas/Niklas Luhmann. Tradução: Ana Cristina Arantes Nasser. $3^{\circ}$ ed. Petrópolis/RJ: Vozes, 2011.

LÜDKE, M; ANDRÉ, M. E. D. A. Pesquisa em educação: abordagens qualitativas. São Paulo: EPU, 1986.

MARINHO, G. Educar em direitos humanos e formar para a cidadania no ensino fundamental. São Paulo: Cortez, 2012.

MARITAIN, Jacques. Rumos da educação. 5. ed. São Paulo: Agir, 1968.

NEVES, Marcelo. A constitucionalização simbólica. São Paulo: Acadêmica, 1994.

PERRENOUD, Philippe. A prática reflexiva no ofício de professor: profissionalização e razão pedagógica/ Philippe Perrenoud. Trad. Cláudia Chilling. Porto Alegre: Artmed, 2002.

PIAGET, Jean. Para onde vai à educação? Tradução de Ivete Braga. Rio de Janeiro: José Olympio, 1973.

PILOTTI, F.; RIZZINI, I. (Org.). A arte de governar crianças: a história das políticas sociais, da legislação e da assistência à infância no Brasil. Rio de Janeiro: Instituto Interamericano Del Niño, Ed. Universitária Santa Úrsula, Amais Livraria e Ed., 1995.

RODRIGUES, Léo Peixoto; NEVES, Fabrício Monteiro. A sociologia de Niklas Luhmann. Petrópolis: Vozes, 2017.

SACAVINO, S. Educação em direitos humanos e democracia. In: CANDAU, V. M.; SACAVINO, S. (Org.). Educar em direitos humanos: construir democracia. Rio de Janeiro: DP\&A, 2000, p. 36-48.

Que significa ser sujeito de direitos? In: SACAVINO, S. B.; CANDAU, V. F. (Coords.). Educação e bullying. Rio de Janeiro: Novamerica/FA Studio Gráfico, 2012.

SÃO PAULO (Estado). Edição revisada e atualizada do Estatuto da Criança e do Adolescente. São Paulo: Governo do estado de São Paulo, Secretaria de Estado da 
Justiça e da Defesa da Cidadania, Conselho Estadual dos Direitos da Criança e do Adolescente, 2012.

SCHILLING, F. (Org.). Direitos Humanos e Educação. São Paulo: Cortez, 2005.

TAVARES, André Ramos. Desjudicialização. Jornal Carta Forense. Disponível em:< http://www.cartaforense.com.br/conteudo/colunas/desjudicializacao/10165>. Acesso em 22 fev. 2018.

VILLAS BOAS FILHO, Orlando. Sociologia Jurídica. Aulas finais. Justiça, argumentação jurídica, acoplamentos e crítica à teoria. Disponível em: < https://lutofoli. wordpress.com/2016/06/16/sociologia-juridica-aulas-finais-justica-argumentacao-juridica-acoplamentos-e-critica-a-teoria/>. Acesso em: 23 nov. 2017. 